DOI: 10.12731/2070-7568-2019-5-71-81

УДК 339.543

\title{
СОВЕРШЕНСТВОВАНИЕ ОРГАНИЗАЦИИ ТАМОЖЕННОГО КОНТРОЛЯ ПРИ ПОМЕЩЕНИИ ТОВАРОВ НА ВРЕМЕННОЕ ХРАНЕНИЕ
}

\section{Павлова А.В.}

В статье представлены законодательные и практические аспекты взаимодействия таможенных органов и околотаможенной инфраструктуры (склада временного хранения) в рамках таможенного контроля при помещении товаров на временное хранение, а также меры по совершенствованию его организации.

Целью настоящего исследования выступает изучение взаимодействия таможенных органов со складами временного хранения в рамках внешнего контроля, осуществляемого таможенными органами РФ при помещении товаров на временное хранение.

Методы и методология: методы эмпирического, теоретического исследования, способы и приемы экономического анализа, дедукиия и индукиия, синтез.

Результатом анализа является разработка рекомендаций по совершенствованию таможенного контроля таможенными органами деятельности складов временного хранения при помещении товаров на временное хранение.

Область применения результатов. Результаты анализа могут быть использованы в деятельности таможенных органов, осущчествляющчих текущчий контроль деятельности складов временного хранения (закрытого и открытого типа).

Новизна исследования. Состоит в разработке рекомендаџий по совершенствованию таможенного контроля, осуществляемого таможенными органами в околотаможенной сфере.

Ключевые слова: таможенные органы; организация таможенного контроля; склады временного хранения; таможенный контроль; временное хранение. 


\section{IMPROVEMENT OF THE ORGANIZATION OF CUSTOMS CONTROL WHEN PLACING GOODS FOR TEMPORARY STORAGE}

\section{Pavlova A.V.}

The article presents the legislative and practical aspects of the interaction of customs authorities and near-customs infrastructure (temporary storage warehouse) as part of customs control when placing goods for temporary storage, as well as measures to improve its organization.

Methods and methodology: methods of empirical, theoretical research, methods and techniques of economic analysis, deduction and induction, synthesis.

The result of the analysis development of recommendations for improving customs control by customs authorities of the activities of temporary storage warehouses when placing goods for temporary storage.

Scope of the results the results of the analysis can be used in the activities of customs authorities, which monitor the activities of temporary storage warehouses (closed and open type).

The novelty of the study. Consists in developing recommendations for improving customs control carried out by customs authorities in the near-customs sphere.

Keywords: customs authorities; organization of customs control; temporary storage warehouses; customs control; temporary storage.

\section{Актуальность}

В результате совершенствования таможенного контроля за операциями на складах в сфере околотаможенной инфраструктуры может быть обеспечена высокая результативность функционирования таможенной системы Российской Федерации.

\section{Материалы и методы исследования}

Исследования в области организации таможенного контроля ведутся достаточно давно, что обусловливало формирование теоретической и аналитической базы знаний. Кроме этого, достаточно 
активно проводятся исследования относительно функционирования около таможенной инфраструктуры, в том числе складов временного хранения (далее - CBX). Однако, в связи с динамичностью происходящих процессов в таможенном деле, в нынешних условиях сокращения времени и документов на первичном контроле, принятием в 2018 году нового законодательства, в том числе касающегося и CBX, требует проведения дальнейших исследований в этой сфере.

\section{Результаты исследования}

В современном законодательстве разделены понятия «временное хранение» и «склад временного хранения». Первое - это процедура, а второе физическое место хранения товара под таможенным контролем. Под временным хранением товаров понимается хранение различной иностранной продукции под таможенным контролем в специально отведенных для этого местах при ее перемещении через таможенную границу Евразийского экономического союза (далее ЕАЭС) из третьих стран до времени выпуска таможенным органом, либо до получения разрешения таможенного органа на вывоз с таможенной территории ЕАЭС [1].

На начало 2018 года в совокупности общая площадь складов уполномоченных экономических операторов, владельцев таможенных, свободных и складов временного хранения в Российской Федерации составляла 4998,35 тыс. м², что более чем в 3 раза меньше, чем в Казахстане. В сравнении же с 2017 годом площадь складских помещений в РФ увеличилась на 14\%. Также в РФ самое большое из всех стран ЕАЭС количество таможенных постов, расположенных на территориях складов, хранящих продукцию под таможенным контролем - а именно, более $30 \%$. Среднее значение площади склада, хранящего товары под таможенным контролем, составляет в РФ более 6 тыс. м² и является самым маленьким значением среди всех стран ЕАЭС. Для сравнения у Казахстана средняя площадь более 47 тыс. м $^{2}$ [7].

Законодательно определено, если предварительно не заявлена процедура таможенного склада, то иностранный товар, перемещае- 
мый через границу ЕАЭС размещается декларантом, перевозчиком или др. лицом определённым Таможенным кодексом Евразийского союза (далее - ТК ЕАЭС) на склад временного хранения и хранится там под таможенным контролем до его выпуска под следующую таможенную процедуру, например, выпуск в свободное обращение и т.д. Сроки и условия хранения, импортируемой продукции на территорию Таможенного союза четко указаны в законодательстве $[1,3]$.

В свою очередь размещение товары и транспортные средства (с фактической выгрузкой или без нее) в местах временного хранения осуществляется на основании полученных от таможенного органа копий транспортных и коммерческих документов на товары. Если в представленных документах не указаны требуемые для помещения товаров на СВХ сведения, то владелец СВХ может запросить декларанта, помещающего товары на СВХ иные дополнительные документы.

Товары и транспортные средства, помещаемые на СВХ в обязательном порядке, проходят через систему контроля на радиоактивность, и принимаются в присутствии декларанта (доверенного представителя) материально ответственным лицом склада по количеству и качеству (сохранности). СВХ ведет учет товаров, помещённых на временное хранение в соответствии с законодательными правилами по осуществлению таможенных операций, установленными локальным документом Федеральной таможенной службы России (Приказ ФТС РФ от 18.03.2019 г. № 444 [4].

На основании Приказа ФТС РФ владелицу склад предписано для ведения учета хранения иностранных товаров, перемещаемых через таможенную границу ЕАЭС использовать три формы документальной отчетности.

Отчетная форма учета иностранных товаров, находящихся под таможенным контролем на СВХ - ДО-1 составляется при приемке товаров на хранение. При отпуске товаров с СВХ также составляется отчетная форма - ДО-2. Третьей обязательной формой отчётности СВХ является ДО-3, которая формируется по первому требованию таможенного органа. Все вышерассмотренные формы предостав- 
ляются таможенному органу в четко установленные сроки [4]. При нарушении установленных сроков владелец СВХ несет административную ответственность.

В целом организация внешнего контроля (осуществляемого таможенными органами) за складскими операциями на СВX можно представить в виде схемы с выделением трех групп основных складских операций: приемка, хранение и отгрузка (рис. 1).

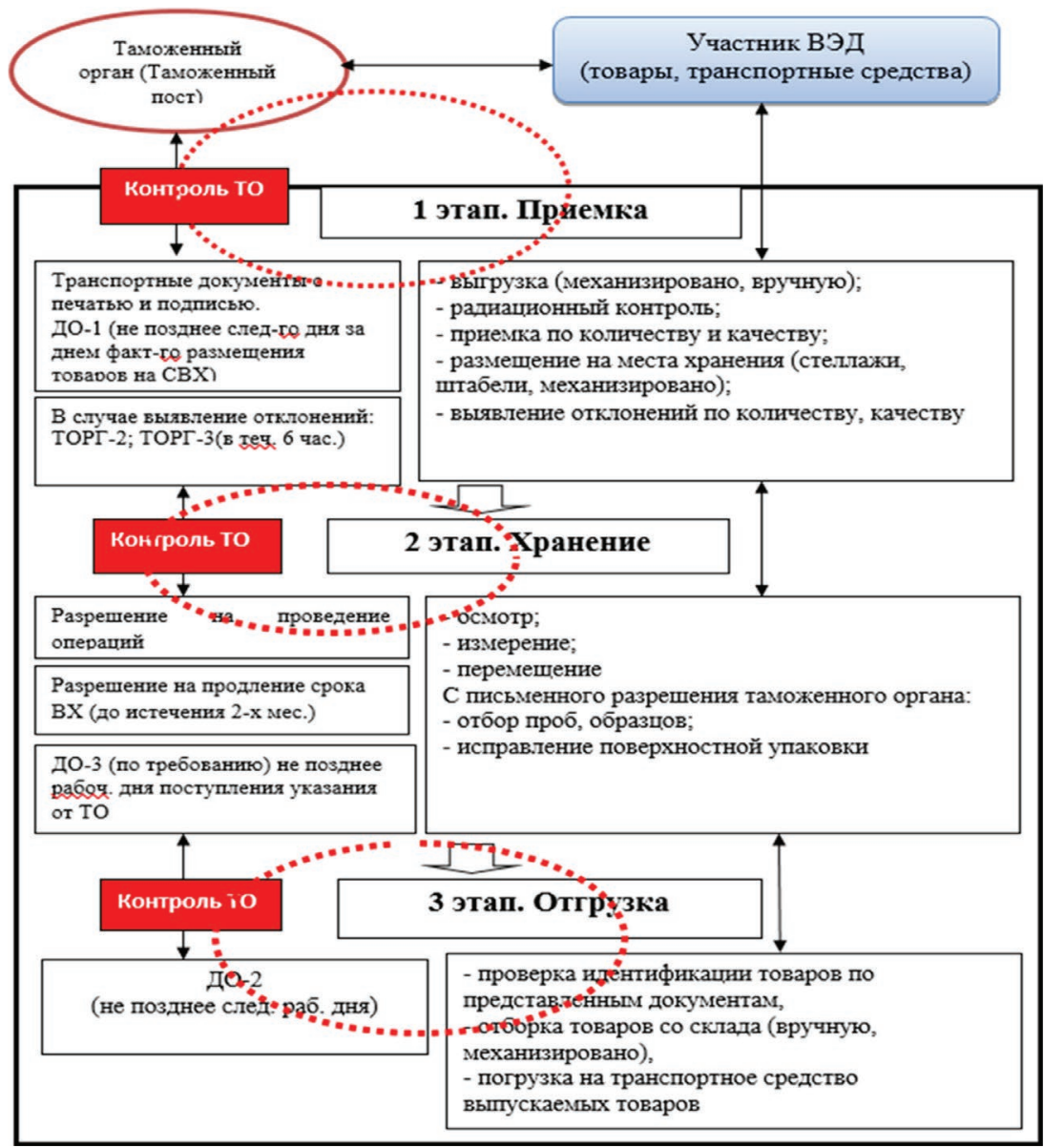

Рис. 1. Организационные основы таможенного контроля за операциями, осуществляемые СВХ (разработка автора) 
Далее рассмотрим частный случай взаимодействия таможенного органа со складом временного хранения по поводу результатов предоставления отчётности о временном хранении товаров.

В таблице 1 приведены данные о нарушении предоставления в таможенный орган (на Каширский таможенный пост) для контроля отёчности по факту приемки, хранения и отгрузки товаров и транспортных средств складом временного хранения АО «Смарт Лоджистик Групп» (табл. 1).

Таблица 1.

Предоставление в таможенные органы отчетности и ответственность СВХ АО «Смарт Лоджистик Групп»

\begin{tabular}{|l|c|c|c|}
\hline \multicolumn{1}{|c|}{ Наименования } & 2016 г. & 2017 г. & 2018 г. \\
\hline $\begin{array}{l}\text { Предоставление в таможенной орган недостоверной от- } \\
\text { чётности (ДО-1 и ДО-2) о весе брутто, стоимости товара }\end{array}$ & 2 & 1 & 2 \\
\hline $\begin{array}{l}\text { Постановления о возбуждении дела об административ- } \\
\text { ной ответственности, в соответствии со ст. 16.15 КоАП } \\
\text { РФ (предоставление недостоверной отчетности) }\end{array}$ & 1 & 1 & 1 \\
\hline $\begin{array}{l}\text { Количество раз предоставленной в таможенной орган } \\
\text { отчётности (ДО-3) с нарушением сроков }\end{array}$ & 4 & 3 & 4 \\
\hline $\begin{array}{l}\text { Постановления о возбуждении дела об административ- } \\
\text { ной ответственности, в соответствии со ст. 16.15 КоАП } \\
\text { РФ (предоставление отчетности в таможенный орган с } \\
\text { нарушением сроков) }\end{array}$ & 1 & 1 & 1 \\
\hline
\end{tabular}

Ежегодно у СВХ АО «Смарт Лоджистик Групп» при осуществлении контроля за складскими операциями таможенным органом выявлялось предоставление недостоверной отчетности о весе брутто, стоимости товара и наименовании товара. В результате возбуждались судебные дела в рамках административной ответственности, предусмотренной ст. 16.15 КоАП РФ в отношении АО «Смарт Лоджистик Групп», т.к. отчеты по форме ДО 1, ДО 2 содержали недостоверные сведения о весе брутто товара, о стоимости товара.

Непредставление, нарушение сроков предоставления, а также предоставление отчетности, регламентированной Таможенным законодательством в таможенные органы в установленный срок, но содержащей недостоверные данные является нарушением и влечет за собой ответственность в форме предупреждения, или в соответ- 
ствии со ст. 16.15 Административного кодекса РФ административную ответственность в виде штрафа [2].

Безусловно СВХ обязан предоставлять достоверную информацию на стадиях приемки, хранения, отгрузки товаров. Однако, до сих пор отсутствует возможность внесения корректировки в ДО-1 и ДО 2.

О данной ситуации свидетельствует судебная практика. Так, к примеру, смысл ответа на вопрос по данному поводу, заданный представителями бизнеса консультанту Департамента бюджетной политики Минфина России, советнику налоговой службы II ранга, специалисту по налоговому закону Лермонтову Ю.М. звучал следующим образом. Проведенный анализ приложений к Приказу ФТС РФ от 18.03.2019 г. № 444 не позволяет в полной мере регламентировать права владельца СВХ, а именно отсутствует четкая методика заполнения отдельных граф отчетной формы ДО-1, ДО-2, ДО-3 [4]. Причем в Приказе не предусмотрен порядок сверки (уточнения) данных, встречной сверки, указанных в ДО-1, ДО-2, ДО-3 между СВХ и таможенным постом на первичном этапе предоставления отчетности. Отсутствует регламентация относительно порядка внесения изменения в отчетность в процессе выявления расхождений $[5,6]$.

Данное обстоятельство, требует внесения изменений в Приказ ФТС РФ от 18.03.2019 г. № 444, где должна быть законодательно предусмотрена возможность внесения корректировок в ДО 1 и ДО 2 , в результате встречной проверки, т.е. необходимо четко регламентировать порядок с установлением сроков. Это снизит нарушения со стороны CВХ и уменьшит затраты времени таможенных органов на судебные разбирательства.

Кроме этого, отмечаются случаи, когда АО «Смарт Лоджистик Групп» не вовремя предоставил отчётность на таможенный пост по операциям на складе временного хранения, что также является нарушением. Однако, необходимо отметить, что длительность таможенного контроля по выпуску товара в 2019 году составляет 4 часа и в течение данного времени к иностранному товару, прибывшему на таможенную территорию ЕАЭС не применяется про- 
цедура временного хранения. А это означает, что владелец СВХ не должен предоставлять отчет в таможенный орган по формам ДО 1 и ДО 2. О правомерности данного суждения свидетельствует судебная практика [8].

Необходимо отметить, что таможенный пост находится на территории СВХ АО «Смарт Лоджистик Групп». Владелец СВХ и таможенный орган ведут отдельный учет и контроль поступления и хранения товаров. Между данными контрагентами ежедневно происходит обмен письменными бумажными уведомлениями и передача информации о поступающих или отгружаемых товарах, что влияет на скорость и правильность выполнения складских операций, так как нет единого программного средства, позволяющего собирать данные о текущих технологических операциях и выдавать отчетность в режиме быстрого реагирования. Поэтому, целесообразно введение в использование между складом временного хранения АО «Смарт Лоджистик Групп» и Каширским таможенным потом автоматизированного информационного программного средства, который позволит осуществить объединение баз данных в единую систему. Развитие такого программного средства будет способствовать обмену информацией между Каширским таможенным постом и СВХ $\mathrm{AO}$ «Смарт Лоджистик Групп», а соответственно и своевременному контролю, а также между отдельными ее подразделениями (ГУИТТ ФТС России, РТУ, таможня).

Современной актуальной задачей в таможенной сфере является совершенствование взаимодействия таможенных органов и предприятий-участников ВЭД, околотаможенной инфраструктуры посредством использования современных информационных технологий.

Резюмируя вышесказанное, можно утверждать, что комплексный электронный подход к учету, контролю и анализу сведений о товарах, помещенных на склад временного хранения, позволяет оперативно получать все необходимые сведения и существенно повышать уровень контроля, сокращать вероятность предоставления недостоверной отчетности с опозданием. 


\section{Заключение}

Таким образом, проведенное исследование с целью совершенствования организации таможенного контроля при помещении товаров на временно хранение позволило выявить ряд факторов, оказывающих существенное отрицательное воздействие на качество проведения таможенного контроля таможенными органами. Совершенствование учета и отчетности СВX позволит существенно сократить временные потери и повысить качество контроля таможенных органов.

\section{Список литературы}

1. Таможенный кодекс Евразийского экономического союза (приложение № 1 к Договору о Таможенном кодексе Евразийского экономического союза) // СПС «Консультант плюс» http://consultant.helpline.ru.

2. Кодекс Российской Федерации об административных правонарушениях от 30.12.2001 № 195-Ф3 (ред. от 02.12.2019) // СПС «Консультант плюс» http://consultant.helpline.ru.

3. Федеральный закон от 03.08.2018 №289-Ф3 (ред. от 01.05.2019) «О таможенном регулировании в Российской Федерации и о внесении изменений в отдельные законодательные акты Российской Федерации» // СПС «Консультант плюс» http://consultant.helpline.ru.

4. Приказ ФТС России от 18.03.2019 №444 «Об утверждении Порядка совершения таможенных операций при помещении товаров на склад временного хранения и иные места временного хранения, при хранении и выдаче товаров...» // СПС «Консультант плюс» http:// consultant.helpline.ru.

5. Постановление ФАС Северо-Западного округа от 30.09.2008 по делу №A56-51144/2007 // СПС «Консультант плюс» http:// www.consultant.ru/cons/cgi/online.cgi? $\mathrm{req}=$ doc $\&$ base $=\mathrm{ASZ}$ $\& n=93173 \# 05976959462811302$.

6. Лермонтов Ю.М. Вопрос:.... Консультация эксперта, Минфин РФ, 2009. https://www.lawmix.ru/finansu/13982.

7. Анализ состояния, динамики и тенденций развития таможенной инфраструктуры в местах перемещения товаров через таможенную 
границу стран Евразийского экономического союза. Аналитический обзор. 2018. http://www.eurasiancommission.org/ru.

8. На склад временного хранения организации в зону деятельности таможенного органа согласно товаросопроводительным документам поступил товар, который принят на временное хранение по форме ДО1 // СПС «Консультант плюс» http://www.consultant.ru/cons/cgi/ online. cgi? req $=$ doc $\&$ base $=$ QUEST $\& n=69648 \# 012068766448778756$.

\section{References}

1. The Customs Code of the Eurasian Economic Union (Appendix No. 1 to the Treaty on the Customs Code of the Eurasian Economic Union) // ATP "Consultant Plus" http://consultant.helpline.ru.

2. The Code of the Russian Federation on Administrative Offenses of December 30, 2001 No. 195-FZ (as amended on December 2, 2019) // ATP “Consultant Plus" http://consultant.helpline.ru.

3. Federal Law dated 03.08.2018 No. 289-Ф3 (as amended on 05/01/2019) "On Customs Regulation in the Russian Federation and on Amending Certain Legislative Acts of the Russian Federation" // ATP "Consultant Plus" http: //consultant.helpline.ru.

4. Order of the FCS of Russia dated March 18, 2019 No. 444 "On approval of the Procedure for completing customs operations when placing goods in a temporary storage warehouse and other places of temporary storage, during storage and delivery of goods ..." // ATP "Consultant plus" http: / /consultant.helpline.ru.

5. Decision of the Federal Antimonopoly Service of the North-Western District of September 30, 2008 in case No. A56-51144 / 2007 // ATP “Consultant Plus" http://www.consultant.ru/cons/cgi/online. cgi?req=doc\&base=ASZ\&n $=93173 \# 05976959462811302$.

6. Lermontov Yu.M. Question:.... Expert Consultation, Ministry of Finance of the Russian Federation, 2009. https://www.lawmix.ru/finansu/13982.

7. Analysis of the state, dynamics and development trends of the customs infra-structure at the places of movement of goods across the customs border of the countries of the Eurasian Economic Union. Analytical review. 2018. http://www.eurasiancommission.org/ru. 
8. The goods that were accepted for temporary storage in the form DO1// ATP "Consultant plus" http://www.consultant.ru/cons/cgi/online arrived at the organization's temporary storage warehouse in the customs authority's activity area according to shipping documents.cgi? req $=\mathrm{doc}$ \& base $=$ QUEST \& n = 69648 \# 012068766448778756 .

\section{ДАННЫЕ ОБ АВТОРЕ}

Павлова Алла Викторовна, кандидат экономических наук, доцент Юридического института, доцент кафедры «Таможенное право и организация таможенного дела»

Федеральное государственное автономное образовательное учреждение выстего образования «Российский университет транспорта»

ул. Образиова, 9, стр. 9, г. Москва, 127994, Российская Федеращия

alpav71@mail.ru

\section{DATA ABOUTH THE AUTHOR}

Pavlova Alla Viktorovna, Candidate of Economic Sciences, Associate Professor Law Institute, Associate Professor of the «Department of Customs Law and customs organization»

Russian University of Transport

9, p. 9, Obraztsova Str., Moscow, 127994, Russian Federation alpav71@mail.ru 